\title{
Review
}

\section{Parkinson's Disease and the Gut: Symptoms, Nutrition, and Microbiota}

\author{
Nehal Yemula $^{\mathrm{a}, *}$, Celina Dietrich $^{\mathrm{b}}$, Vaclav Dostal $^{\mathrm{a}}$ and Michael Hornberger ${ }^{\mathrm{b}}$ \\ ${ }^{a}$ Norfolk and Norwich University Hospital, Norwich, United Kingdom \\ ${ }^{\mathrm{b}}$ Faculty of Health and Medical Sciences, University of East Anglia, Norwich, United Kingdom
}

Accepted 22 June 2021

Pre-press 7 July 2021

\begin{abstract}
Parkinson's disease (PD) is the second most common neurodegenerative disease worldwide, characterized by symptoms of bradykinesia, rigidity, postural instability, and tremor. Recently, there has been a growing focus on the relationship between the gut and the development of PD. Emerging to the forefront, an interesting concept has developed suggesting that the initial pathophysiological changes occur in the gastrointestinal tract before changes are seen within the brain. This review is aimed at highlighting the relationship between PD and the gastrointestinal tract, along with the supporting evidence for this. Firstly, we will focus on the gastrointestinal conditions and symptoms which commonly affects patients, including both upper and lower gastrointestinal issues. Secondly, the impact of nutrition and diet on neurological health and PD physiology, with particular emphasis on commonly consumed items including macronutrients and micronutrients. Finally, variability of the gut microbiome will also be discussed and its link with both the symptoms and signs of PD. The evidence presented in this review highly suggests that the initial pathogenesis in the gut may proceed the development of prodromal PD subtypes, and therefore building on this further could be imperative and lead to earlier diagnosis with new and improved therapeutics.
\end{abstract}

Keywords: Gut, microbiota, nutrition, Parkinson's disease

\section{BACKGROUND}

Parkinson's disease (PD) is characterized by degeneration of the dopaminergic neurons of the substantia nigra and spread of alpha-synuclein enriched Lewy bodies (LB) to other cortical and subcortical brain areas, particularly the basal ganglia [1, 2]. The development of LB arises from an initial template formed from pathological alpha-synuclein, which instigates seeding of nearby alpha-synuclein proteins. This triggers a shift from a benign $\alpha$-helical structure to a toxic, insoluble $\beta$-pleated sheet structure protein, which aggregates to form LB [3]. These

\footnotetext{
*Correspondence to: Dr. Nehal Yemula, Norfolk and Norwich University Hospital, Colney Lane, Norwich, NR4 7UQ, United Kingdom. Tel.: +44 7794586152; E-mail: nehal_95@ hotmail.com.
}

seeds may then disseminate throughout nearby and distal neurons, leading to the development and sites of Lewy pathology (LP) [4].

The nigrostriatal pathway plays an important role in the pathophysiology of PD. The levels of dopamine decrease due to the breakdown of the substantia nigra, in particular, within an area called the pars compacta [2]. The dopaminergic changes in PD lead to the characteristic motor symptoms of PD such as muscle rigidity, bradykinesia, tremor, and postural instability [5].

However, other symptoms, such as anosmia and autonomic dysfunction are also highly common in PD [6]. Of particular importance, gut symptoms have received increased attention with new evidence suggesting that PD pathophysiology may start in the gut. This highlights an underexplored area of research and will therefore be a focus of this review. 
The gastrointestinal microbiota could play an important role in the development of PD as a link between the intestinal microbiota, neurodevelopment and neurological diseases are increasingly recognized. Neurological function is influenced by neuropeptides, neuronal hormones and many other metabolites produced within the gut, whilst the gut itself is heavily influenced by the central nervous system (CNS) [7]. The gut microbiome, made up of bacteria, fungi and archaea form a diverse community that is highly variable and unique to each individual and encompasses a number of crucial functions, including maintaining metabolic homeostasis, vitamin biosynthesis, and drug modification [8].

Gut dysbiosis, defined broadly as an alteration of the gut microbiome, has been associated with a number of inflammatory-driven diseases including inflammatory bowel disease (IBD), Alzheimer's disease (AD), and obesity [9]. Furthermore, dysbiosis is associated with the development of low-grade inflammation, increased oxidative stress, cellular degeneration, and disturbance of the blood-brain barrier [10]. Particular focus has aimed at investigating the microbiome in PD, with increasing evidence demonstrating differences in the gut microbiota composition between PD patients and healthy controls. The intestinal microbiota in PD may also be involved in the modulation of a-synuclein aggregation and may further play a role in short chain fatty acid metabolism, alpha-synuclein pathology and microglial activation $[8,11,12]$. Finally, levels of certain bacterial species may influence PD symptomology [13].

This review will cover the theory and evidence behind the reasons why PD may start within the gut, the influence of nutrition on the risk of PD and how variances in gut microbiota composition may contribute to the PD origins and associated symptoms. Our evidence for this review is sourced from key papers published and cited in this field, including case-based discussions to meta-analyses.

\section{BRAAK AND THE GUT THEORY}

The onset of sporadic PD is unknown, but the Braak hypothesis offers to explain a mechanism for this. Braak et al. proposed the dual-hit theory which suggests that sporadic PD starts in two places-the neurons of the olfactory system and the gastrointestinal tract (GIT) [14]. This review will only focus on the GIT aspect of Braak's theory and will only briefly touch upon the involvement of the olfactory network.
Braak hypothesized that a foreign pathogen, either bacterial or viral, triggers a response which leads to LP that affects the olfactory and GIT system [15]. Subsequently, neurons allow the retrograde transmission of alpha-synuclein enriched LB to the CNS from the olfactory and the vagus nerve, respectively. The transmission of alpha-synuclein pathology is believed to spread across the nervous system through a 'prion-like' fashion [16].

A fundamental aspect of Braak's theory is the movement of alpha-synuclein from the enteric nervous system (ENS) to the CNS via the vagus nerve and dorsal motor nucleus of vagus within the medulla oblongata [17]. The ENS is a network of neurons within the gut wall which works separately from the CNS [18]. The ENS consists of two plexuses, myenteric and submucosal, and has a number of different roles including regulating motility, mucosal blood flow and water transport [19]. The vagal nerve plays an important part in functions of the body, e.g., stimulating salivation, gut peristalsis, and bladder contraction [20].

Composed of six stages, disease progression is determined by the Braak staging system. Each stage represents a site of LP, starting from the ENS and ascending through the brain. Stages 1 and 2 demonstrate hindbrain pathology, whilst stages 3 and 4 involve the midbrain, where motor symptoms become recognizable. Cognitive symptoms are apparent in stages 5 and 6 as the full neocortex is affected [21].

Braak's theory dovetails with clinical evidence of gastrointestinal symptoms, including dysphagia, constipation, early satiety, bloating, and non-specific abdominal pain. The presence of LP within GIT neurons or the ENS has been reported [22-32] and LP can be seen within the ENS up to 10-20 years prior to the diagnosis of PD, suggesting gastrointestinal dysfunction may precede the first onset of motor symptoms [33]. Two independent histological studies have reported an abundance of alpha-synuclein within the vermiform appendix and have suggested that an appendectomy, may both lower the risk of developing PD and delay the age of onset [34]. A large, nested control study conducted by Liu et al also concluded that an appendectomy was associated with a lower risk of PD [35], but interestingly, a 2021 meta-analysis demonstrated no significant difference in emergence of PD between patients with and those without an appendectomy history [36]. Moreover, LP findings have also been replicated in animal models, with aggregations of alpha-synuclein found in the GIT of both early and advanced PD [37, 38]. 
Retrospective autopsy-based studies have shown LP in the peripheral vagal nerves [39] and this is significant as swallowing and excessive salivation difficulties are common in PD patients [40]. Interestingly, truncal vagotomy has been suggested as a protective factor in reducing the long-term risk of PD [41]. Although, such a radical procedure and its implications need to be clearly further investigated [42].

Despite the evidence suggesting that PD may start within the gut, limitations exist to this concept. For the prion hypothesis to work in the Braak staging criteria, Lewy pathology must be seen in the lower brainstem prior to the appearance of Lewy pathology in higher structures, e.g., stage 1 involves the dorsal motor nucleus of vagus in the medulla oblongata as the first site of spread within the brain. However, patients have been found to have pathology in higher structures of the brain, including severe disease in the substantia nigra (stage 3) without involvement of the lower brainstem [43]. Therefore, perhaps alternative routes of LP spread may be present in the development of PD pathology. Furthermore, alphasynuclein is also a major histopathological hallmark of a number of different diseases such as $\mathrm{AD}$, dementia with Lewy bodies, and multiple system atrophy, but these conditions do not show the same distribution of pathology according to the prion hypothesis and Braak staging system $[4,44]$. The question also remains whether the gut microbiota has an impact on the genesis of alpha-synuclein within the gut.

Another key aspect is the movement of alphasynuclein from the ENS to CNS. This mechanism has been countered by a study which suggests the transmission of pathology actually moves from the brain to the GIT founded on results displaying higher density levels of phosphorylated alpha-synuclein in the spinal cord and peripheral nerves compared with the gut [45]. Moreover, not all PD patients have shown LP within the ENS [46]. Over the course of the disease progression, younger patients had pathology associated with the Braak staging model over the course of their disease compared with elderly patients with a shorter disease whose symptoms did not correlate [47]. Consequently, this could mean the staging system may be more inclined to certain phenotypes.

Question marks also exist as to whether Lewy pathology is beneficial in neurodegenerative disease. Lewy bodies have been theorised to enclose insoluble, misfolded alpha-synuclein and help facilitate aggresome-like degradation [48, 49]. This opposes the current views that Lewy pathology is a sign of neurodegeneration.
Finally, while the degeneration of the nigrostriatal dopamine pathway is the key characterization of PD, other non-dopaminergic systems also contribute to the pathophysiology. Affected neurotransmitters in PD also include noradrenaline, serotonin, GABA, and acetylcholine [50]. Degeneration of these neurons can lead to abnormalities attributing to both motor and non-motor symptoms. Braak's theory has little reference to this and their involvement in PD may be greater than first imagined [51].

\section{GIT SYMPTOMS}

Aside from motor irregularities, non-motor symptoms involving the GIT are common in PD. These include abnormal salivation, dysphagia, constipation, abdominal bloating, early satiety, and fecal incontinence [52]. Here we will take a closer look at the reported symptoms and its link with PD.

\section{Constipation}

Constipation occurs due to delayed intestinal transit time and decreased GI motility, with effects displayed in the small and large bowels [52, 53]. Individuals with chronic constipation have a 3-11-fold increased risk of developing PD [54], and data from both prospective and retrospective studies suggests constipation becomes evident between an average of 15.6-24.0 years before diagnosis [55]. Interestingly, middle-aged men with infrequent bowel movements ( $<1$ bowel movement/day), had a 4 times increased risk of PD diagnosis over the next 20-25-year period compared with the same population with normal bowel movements [56]. Intestinal complications arising from constipation such as sigmoid volvulus, bowel perforation, and asymptomatic megacolon may also occur [57].

\section{Defactory difficulties}

Defecation difficulties are common in patients with $\mathrm{PD}$, may appear early in the disease process [58]. Incoordination of the muscles of defecation such as puborectalis, abdominal muscles, and diaphragm may result in ineffective elimination [59]. A vital part of the defecation process involves both the internal and external anal sphincter muscles, with impaired relaxation of these sphincters confirmed through defecography and anorectal manometry studies [60, 61]. Consequently, as a result of defecation difficulties and fecal impaction, a complication of fecal 
incontinence arises, and this can be hugely distressing to the patient [62].

\section{Inflammatory bowel disease}

Nationwide population-based studies have found a significantly increased risk of PD in patients suffering from IBD [63, 64]. IBD has a genetic susceptibility with LRRK2, the same gene involved in sporadic PD [65]. It is known that the risk of ulcerative colitis decreases with smoking [66] and a recent meta-analysis has also shown that long-term smoking reduces the risk of PD [67]. Smoking is hypothesized to affect the gut microbiota and reduce the production of proinflammatory cytokines, thus lessening intestinal inflammation [68].

\section{Early satiety and bloating}

Early satiety and bloating are due to impaired gastric emptying with magnetic resonance imaging and electrogastrography showing gastric motility abnormalities $[69,70]$. Loss of neuronal function within the myenteric plexus and LB inclusions embodied within the vagus nerve slowing down intestinal peristalsis may cause these abnormalities [71, 72]. Gastroparesis could have implications involving absorption of L-Dopa and thus influence the degree of motor symptoms [73], whilst small bowel dysmotility may cause abdominal bloating and predispose to small intestinal bowel overgrowth (SIBO) [74].

\section{Dysphagia}

Dysphagia develops during the disease progression in over $80 \%$ of patients [75]. In one-third of patients, the issue of swallowing arises from the motor symptoms of bradykinesia and tongue motor control [76]. Furthermore, issues with swallowing reflex and esophageal sphincter contractions have been observed [77]. LB have been detected in the esophageal myenteric plexus [78] with high resolution esophageal manometry studies, barium swallow studies and scintigraphy studies showing abnormalities with the esophageal body and lower esophageal sphincter [79-81]. LP has also been discovered in the glossopharyngeal nerve and internal superior laryngeal nerve in patients with dysphagia [82]. The complications of dysphagia are serious, including malnutrition, dehydration, and aspiration pneumonia [83].

\section{Hypersalivation}

Hypersalivation and sialorrhea occurs in the later stages of the disease [84]. It is thought to occur in patients due to decreased swallowing frequency rather than increased saliva production [85] whilst other motor features, e.g., hypomimia and stooped posture, may exacerbate drooling [86]. Additionally, sialorrhea has been linked with an increased risk of respiratory infection in patients with daily drooling [87].

\section{DIET AND NUTRITION}

Environmental factors are thought to contribute to the pathogenesis and development of PD. Recent research suggests that certain compounds and nutrients may trigger the disease process whilst others may in fact be neuroprotective [88]. The composition of gut microbiota is also heavily influenced by diet with research indicating the effect of diet on neurological health is based on the gut microbiota population rather than diet-induced neuro-inflammation [89]. Microbiota dysbiosis has been linked to the type and amount of consumption including dietary macronutrients, vegetables and dietary patterns such as the Mediterranean diet (MD). This aspect of the review focuses on certain dietary compounds which my play a role in PD physiology.

\section{Caffeine}

Caffeine has several health benefits including a positive influence on cardiovascular health [90]. An inverse relationship between caffeine consumption and the risk of developing PD has been reported. A variety of epidemiological studies have implied coffee consumption as a causal factor [91-93]. Experimental models have suggested adenosine A2A receptors, located with D2 dopaminergic neurons within the striatum, are involved in the mode of action [94]. Caffeine may antagonize the A2A receptors and accordingly stimulate the D2 receptors, leading to increased motor activity and motor symptom improvement [95]. The cytoprotective effects of caffeine have been displayed through activation of cell signaling pathways, particularly P13K/Akt; an important pathway in downregulating neuroinflammation [96]. Moreover, further animal studies have shown caffeine increased the effect of L-dopa and thereby augmenting dopamine levels [97]. 
Tea

Tea has been implicated as a neuroprotective agent for PD [98], although some studies have contested this [99]. A 2012 meta-analysis confirmed tea drinking was protective but with no real dose-response relationship [100]; however, a 2014 meta-analysis did find a linear-dose relationship [101]. A 2019 metaanalysis confirmed tea consumption was associated with a reduced risk of $\mathrm{PD}$, and in particular, people who drink more than one cup of non-black tea daily [102]. A range of natural products within tea such as polyphenols, methylxanthine, and caffeine have been linked to a number of beneficial health effects [103]. Epigallocatechin gallate (EGCG), a polyphenol, may promote neuroprotection through inhibiting the production of free radicals and pro-inflammatory markers within the brain [104]. Theanine increases dopamine levels in the brain [105] and flavonoids may help to facilitate increased brain blood flow through their anti-inflammatory effects on the circulatory system [106].

\section{Dairy}

Dairy products, e.g., milk have been associated with a higher incidence of PD through a number of worldwide epidemiological studies [107, 108] and this association with milk is stronger than other products such as cheese and yogurts. Interestingly, a dose-response meta-analysis of prospective cohort studies determined a $17 \%$ increased PD risk for every $200 \mathrm{~g} /$ day increment in milk intake [109]. Moreover, it is also thought high consumption of dairy products may lead to low serum uric acid levels in individuals through the influence of casein on uric acid concentrations [110]. High serum uric acid levels may reduce the risk of PD and the duration of the disease [111-113]. Interestingly, this protective effect of uric acid has only been seen in men $[88,114]$.

\section{Fruit and vegetables}

Encompassing a number of antioxidants, a diet high in fruit and vegetable consumption has been found to lower the risk of PD [115]. Recently, the MD has been increasingly explored to determine its effects on neurological health [116]. The MD is characterized by high amounts of olive oil, vegetables, fruits, fish and lower consumption of meats and animal fats. A meta-analysis demonstrated good adherence to the MD lead to significant improvement in health status and reduced incidence of PD [117]. Nutritional modulation of ageing pathways involving brain atrophy and neuroinflammation induced by the MD may explain the lower risk in PD.

\section{Vitamins}

Vitamin intake could be useful in the prevention of PD. A meta-analysis has detected lower levels of Vitamin B12 in PD patients compared with controls whilst supplementation of Vitamin B6 could be associated with a decreased risk of PD [118, 119]. Vitamin B6, B9, and B12 are involved in homocysteine metabolism, with high levels of homocysteine known to cause neurotoxicity [120]. It is still unclear in the context of PD, whether high levels of homocysteine are due to medications such as L-dopa or are involved at first-hand [121]. Vitamin C, abundant in the CNS, is thought to be neuroprotective but the association is controversial [122]. Intriguingly, Vitamin $\mathrm{D}$ indirectly influences the breakdown of dopaminergic neurons within the substantia nigra through regulation of calcium [123]. Vitamin D deficiency has been detected in patients, with supplementation improving PD motor symptoms [124, 125]. Higher dietary consumption of vitamin $\mathrm{E}$, another neuroprotective agent, was also found to reduce PD risk $[122,126]$.

Fats

The relationship with the consumption of dietary fats with PD risk has been widely reported, albeit with inconsistent findings. A 2019 meta-analysis expressed an association between high intake of animal fat and the risk of PD, and this depends on the subtype of fat, for instance, arachidonic acid and cholesterol may increase PD risk [127]. Interestingly, N-3 polyunsaturated fatty acids (PUFAs) may reduce PD risk [128]. Located in neuronal membranes, an abundance of PUFAs within the brain is thought to provide a neuroprotective effect [129], whilst it has been demonstrated that PUFA deficiency may lead to poor brain function [130]. The evidence that PUFA may decrease PD risk is further strengthened as $\alpha$ linolenic acid, a fatty acid precursor, demonstrates an inverse association with PD risk [131]. A ketogenic diet trialed in animal and clinical trials was successful in improving parkinsonism [132] with a Unified Parkinson's Disease Rating Scale (UPDRS) improvement [133]. However, this specific diet trialed 
contained low protein which could increase the bioavailability of L-dopa [134].

\section{Carbohydrates}

Similar to dietary fats, studies evaluating the impact of carbohydrates has also been reported, with conflicting reports [135]. Carbohydrates may influence dopamine production in the brain by initiating easy passage of its precursor, tyrosine, through the blood-brain barrier [136]. Additionally, an insulin surge through the consumption of high glycemic index carbohydrates may also increase dopamine production [137]. A pilot randomized controlled trial investigating the efficacy of a low-fat, high carbohydrate diet against a ketogenic diet demonstrated a significant improvement in both motor and nonmotor symptoms, albeit a greater improvement in the ketogenic diet [138]. Nonetheless, the link between carbohydrate consumption and PD risk may not be clinically significant. For instance, a high carbohydrate diet is known to cause an increased risk of type 2 diabetes mellitus (T2DM) [139]. Theoretically, these patients with T2DM should have a lower risk of PD due to the effect of carbohydrates on dopamine production. However, the link between T2DM and PD has been extensively investigated, with a systematic review demonstrating inconsistent reports [140]. Therefore, clinically a balanced healthy diet should always be advised in all patients as primary and secondary prevention to reduce risk of other diseases, e.g., cardiovascular, metabolic. On a side note, the effect of certain anti-diabetic medications in patients with both PD and T2DM may have an important role in influencing PD symptomology. Excitingly, incretin mimetics such as exenatide may be neuroprotective and in a double-blinded randomized control trial demonstrated a statistically significant improvement in the UPDRS score [141]. Possible reasons for the neuroprotective effects of incretin mimetics may include increase tyrosine levels in neurons and inhibition of microglial activation [142]. Research into these medications may well lead to future therapeutic treatments for patients with or without diabetes.

\section{THE GUT MICROBIOTA}

Growing evidence suggests that a relationship exists between PD and the gastrointestinal microbiota. The GIT consists of an incredibly diverse and complex population of microorganisms, which coexists symbiotically with the host and plays a crucial rule in enhancing overall host health [143]. In early life the microbiota changes rapidly and is fundamental in the development and promotion of the immune system [144]. By the age of 3 years the gut microbiota stabilizes but remains susceptible to a large range of environment and host factors. A change in the microbial composition towards a maladaptive and pathogenic profile [145], also called dysbiosis, has been associated with a wide range of conditions including type 1 diabetes mellitus, IBD, and a range of neurodegenerative conditions such as AD, amyotrophic lateral sclerosis, and PD [146, 147].

A number of studies reported that patients with PD were found to have significantly reduced levels of bacterial diversity when compared against a healthy population [148-154]. Until 2019, 16 human case control studies have investigated the role of gut microbiota in PD, with over 100 different bacterial taxonomic levels reported. Between healthy controls and PD patients, all 16 case-control studies reported statistically significant differences [13]. A recent 2021 meta-analysis by Romano et al confirmed consistent differences between the average gut-microbiota levels between healthy controls and patients with PD [12].

The bacterial taxa highlighted in this review were chosen as previous studies including the metaanalysis by Romano et al, have shown that there is distinct variation in the gut microbiota profiles between healthy controls and PD patients. Different relative abundances of the selected taxa have been shown by other studies to be associated with PD physiology and symptomology.

The composition of gut bacteria has been shown to be different in patients with both early and advanced PD [154]. Intestinal microbial overgrowth is due to an increase in coliform bacteria and has been discovered to be a common occurrence in PD patients [155, 156]. Concentrations of urinary indican, a marker for microbial dysbiosis, demonstrated a nearly two-fold increase $[157,158]$ which indicates that microbiota may play a part in PD pathogenesis.

\section{Ralstonia, Eubacterium, Enterobacteriaceae}

Fecal microbiota from PD patients shows higher levels of pro-inflammatory gram-negative bacteria from the Ralstonia genus [159]. Higher UPDRS scores in PD patients were also associated with increased levels of Eubacterium eligens, Eubacterium rectale, and Eubacterium hallii, corresponding with a worse disease state [150]. Furthermore, 
fecal analysis has shown an increase in Enterobacteriaceae family bacteria which may be linked with worsening postural instability and gait disturbances [151].

\section{Prevotella}

In contrast, beneficial and anti-inflammatory bacteria were reduced in feces, most notably with lower levels of prevotellaecea [160]. Prevotella, a gramnegative bacterium and belonging to the phylum Bacteriodetes, is important in the degradation of complex carbohydrates to produce short-chain fatty acids. Folate and thiamine are also by-products and alongside short-chain fatty acids promote a healthy microbial environment [161, 162]. Decreased levels of Prevotella are associated with reduced mucin proteins [163]. Mucin proteins are required to line the mucosal surfaces and maintain the epithelial barrier of the intestines. Low mucin leads to increased intestinal permeability, a sign associated with PD [164]. Additionally, Prevotella levels were also decreased in idiopathic rapid eye movement behavior sleep disorders (IRBD) [165]. This is intriguing as the onset of IRBD in the majority of times precedes the diagnosis of PD and in the early stages, could potentially act as a clinical biomarker [166]. Prevotella copri, a species of the genus Prevotella, was also lower in abundance in a number of different neurodegenerative conditions, e.g., multiple system atrophy and multiple sclerosis. This suggests that higher levels of Prevotella may play a protective role and may be a promising future therapeutic target [149, 159, 167]. However, as Prevotella encompasses a number of different species, it may be unreliable to generalize these findings.

\section{Lactobacillus}

Lactobacillus, a gram-positive bacterium belonging to the Phylum Firmicutes, were found to also be affected in PD [12]. Higher levels of Lactobacillus combined with a decrease in Prevotella has been associated with lower concentrations and altered secretions of ghrelin [152]. Ghrelin, known as the 'hunger hormone', is released by the stomach and small intestine [168]. The relationship between ghrelin and PD is not fully understood, but ghrelin may be involved in the maintenance of the nigrostriatal dopamine pathway [163]. Increased levels of Lactobacillus may be caused by frequent constipation as Lactobacillus is associated with IBS type consti- pation [169]. Its potential as a probiotic treatment, particularly using the strain Lactobacillus casei, which has been observed to be an effective therapeutic in PD through improving stool consistency and bowel habit [170], is currently underway.

\section{Blautia and Coprococcus}

A decrease in anti-inflammatory species from the Blautia and Coprococcus genus were also confirmed in fecal microbiota studies [12]. Bacterial strains belonging to these two taxa produce the short-chain fatty acid butyrate which is important in stimulating intestinal mucus and regulating tight junction proteins to maintain the epithelial lining of the colon [171]. As only small amounts of butyrate are found in natural food e.g., milk and cheese, the majority of butyrate is sourced from the gut [172]. The levels of gut butyrate may influence GIT symptoms such as constipation, with butyric acid found to increase peristaltic efficiency by improving the contraction of intestinal smooth muscle and regulating intestinal neuropathways [173]. Butyric acid may also cause reduced water secretion from the GIT, which could also contribute to constipation [174]. Perhaps supplements with sodium butyrate may be beneficial as this has been seen to improve locomotor symptoms [175].

\section{Akkermansia}

Species from the Akkermansia genus of the Verrucomicrobia phylum were higher in numbers in PD patients [12]. Representing between 1-4\% of gut microbiota, Akkermansia has been associated with conditions like obesity and diabetes and is known to help regulate mucin levels within the intestinal tract [176]. The combination of the mucous layer made from mucin and the gut microbiome is recognized as the biofilm [177]. The biofilm helps protect against intestinal injury and consequently intestinal permeability. Intestinal permeability or 'leaky gut' can generate both local and systematic inflammation. High levels of Akkermansia may cause intestinal permeability as the species requires mucous for energy thereby causing a breakdown of the biofilm [178].

\section{Helicobacter}

Helicobacter pylori (H.pylori) infections and subsequently gastric ulcers are less common in the general population than in PD patients $[179,180]$. Tan et al reported $H$. pylori in $32 \%$ of PD patients 
[181], whilst several case control studies found the H. pylori antibody to be five times more common in PD [182]. A double-blinded randomized control trial to investigate the relationship between idiopathic PD and $H$. pylori, was shown to worsen stride length and rigidity in PD in patients with $H$. pylori and eradication of the bacteria was found to improve symptoms- $H$. pylori may impede the absorption of levodopa which leads to worsening of motor impairments [183]. Follow up studies with H. pylori revealed an elevated immune response, with high levels of natural killer cells and CD4 Thelper cells associated with worsening PD symptoms; this includes increased muscle rigidity and decreased free-walking speed [184]. Two proposed theories explain the pathophysiological relationship between H. pylori and PD. Firstly, H. pylori causes a neurotoxic effect by increased cholesterol glucosides, and this subsequently degrades dopaminergic neurons within the brain [185]. Secondly, poor immune control leads to $H$. pylori crossing the blood-brain barrier and this initiates apoptosis of dopaminergic neurons [186, 187].

\section{Small intestinal bacterial overgrowth}

A recent meta-analysis found a strong association between SIBO and PD, with around $50 \%$ of patients diagnosed with SIBO (188). Gastroparesis and abnormal motility of the GIT are cited as possible causes [189]. Disruption of the small bowel epithelium may lead to increased intestinal permeability, therefore making it more prone to bacteria and foreign pathogens [74]. Similar to H. pylori, this condition is linked to motor dysfunction and treatment with antibiotics improves symptoms. Finally, the same study also noted increased bacterial overgrowth may predispose to the poor absorption of L-Dopa [189].

\section{Interpreting results}

However, it is important to note that these results must be taken with caution. Investigating the variances in gut microbiota is a challenging area of research, particularly because of differences in study methodologies and the inherently large variability of gut microbiota composition between participants. Boertien et al. discussed the implications of comparing and analyzing data between gut microbiome studies in PD. From variation in sample size to influence of confounding variables, many factors need to be considered when interpreting the inconsistency of study results. It is therefore difficult to establish whether taxonomic changes are related to PD pathology. Robust methodology through standardization of research protocols and collection of confounders is important to produce data homogenization. An integrative dataset with all sequencing data should be available publicly to address these confounders, with further expansion of atypical parkinsonism and prodromal PD data required to thoroughly investigate this area [13].

\section{Prodromal PD}

Heinzel et al. recently investigated the associations between gut microbial composition, prodromal and risk markers of PD. Markers including constipation, physical activity, smoking, IRBD and subthreshold parkinsonism were associated with variances in gut composition, with findings suggesting the microbial composition of the gut may be altered in the prodromal phase. Although, it was noted that other predictive markers of prodromal PD did not show a significant link with microbial changes such as olfactory loss, positive family history of PD, orthostatic hypotension, depression, and erectile and urinary dysfunction [190].

\section{CONCLUSION}

In conclusion, increasing evidence suggests a strong relationship between gut microbiota and PD. The gut influence is thought to be larger than first believed, with Braak's hypothesis the most promising in explaining a GIT impact in PD pathophysiology. This theory has been supported through a range of pathological studies investigating the role of alpha-synuclein and other neuropathological changes within the disease progression. Clinical studies have provided further supplementary evidence of GIT symptomology, dietary impact, and changes in gut microbiota levels in PD.

The variety of GIT symptoms and conditions experienced by patients may be associated with the underlying pathophysiological origins of the disease. Recognition of these symptoms in the early stages of the disease could be important indicators leading to a prompt diagnosis and improved holistic management. However, it is important to note that the gut/microbiota may not be entirely involved in the prodromal phase of all PD patients and as such a 
focused systemic approach should be undertaken as suggested by Heinzel et al. [190]. Furthermore, at present, limited studies have explored the role of gut symptoms in early-disease stages. By detecting GIT symptoms in the early stages, it could be possible to associate this with the initial pathophysiological changes.

Current evidence indicates that diet is important in PD development and progression. Food therapies could not only be imperative in lowering the risk of PD, but also improve symptom severity. Combined with current medication, nutritional approaches might also improve bioavailability and pharmacological effects. The majority of dietary findings in PD studies are based on either epidemiological or metaanalyses, with little information on how diet impacts on an individual level. More research in this area is needed as it may provide novel insight into the importance of nutrition on symptom severity and gut microbiota changes, which in turn could provide the basis for new treatments. The link between PUFA's and PD should be thoroughly investigated as this is still unclear. Studies have suggested PUFA's may have anti-inflammatory and neuroprotective properties, with increased consumption of PUFA's shown to reduce PD risk. However, other studies suggest PUFA's may lead to neuronal degeneration within the substantia nigra through the involvement of oxidative radical formation. With further investigation, these food compounds could easily be tailored in everyday diet to adjust the risk of PD accordingly. Moreover, the MD could also be a key step in PD research. The clear health benefits of this diet are well known, and through either a prospective cohort or case-control study, the results may impact on our everyday diet. Finally, vitamins have been thought to influence the risk of PD although the link is still debatable. Vitamins $\mathrm{C}, \mathrm{D}$, and $\mathrm{E}$ are theorized to be neuroprotective, and through investigating the role of multivitamins in PD, perhaps by taking a daily multivitamin tablet, the advantages may include reducing risk, improving symptomology, and with widespread multisystem benefits.

There are limitations to our review article which are needed to be taken into consideration. For the purpose of the current review, we deliberately chose a narrative review since the current research body on this topic is very limited making a systematic review less feasible. Instead, we wanted to raise the awareness of the topic and its current research findings to the wider research community. Throughout this paper we have added limitations and future directions highlighting the need for forthcoming systematic reviews. We have also used recent high-quality research where applicable, e.g., from meta-analyses and articles to ensure the content in our review is reliable and reduce bias.

As summarized in this review, the role of gut microbiota in PD is suggested to be significant. Variances gut in the microbiome profiles of PD patients are associated with dysbiosis which in turn is linked with gastrointestinal disease and parkinsonian features. Lactobacillus and Prevotellacea are the two most exciting bacterial taxa which are linked with PD. In particular, the role of these species within probiotics and fecal transplantation may be a successful future treatment in PD. A study researching these specific probiotics in a prospective cohort study of PD patients would be a step in discovering the viability of these treatments. It would be also of interest if research explored the impact of nutrition on gut microbiota, particularly in members of the same household. The rationale behind recruiting cohabiting couples who live together involves similar dietary patterns and environmental microbiota. This dyadic approach has been shown to reduce the variability in background diet patterns and microbiota composition. Finally, to note, there has been little exploration into the different stages of PD and gut microbiota. Longitudinal studies in the prodromal as well as clinical phase of PD considering multi-omics, environmental and deeply phenotypic clinical data may advance our understanding of the links between microbiota and PD.

\section{CONFLICT OF INTEREST}

Vaclav Dostal is a consultant for Abbvie and serves on the advisory boards for Abbvie and Novartis. Michael Hornberger is a consultant for Abbvie and serves as a non-executive director on the advisory board of the Eastern Academic Health Sciences Network. No other authors have any conflicts to report.

\section{REFERENCES}

[1] Wright Willis A, Evanoff BA, Lian M, Criswell SR, Racette BA (2010) Geographic and ethnic variation in Parkinson disease: A population-based study of US Medicare beneficiaries. Neuroepidemiology 34, 143-151.

[2] Galvan A, Wichmann T (2008) Pathophysiology of parkinsonism. Clin Neurophysiol 119, 1459-1474.

[3] Goedert M, Masuda-Suzukake M, Falcon B (2017) Like prions: The propagation of aggregated tau and alphasynuclein in neurodegeneration. Brain 140, 266-278. 
[4] Visanji NP, Brooks PL, Hazrati LN, Lang AE (2013) The prion hypothesis in Parkinson's disease: Braak to the future. Acta Neuropathol Commun 1, 2.

[5] Moustafa AA, Chakravarthy S, Phillips JR, Gupta A, Keri S, Polner B, Frank MJ, Jahanshahi M (2016) Motor symptoms in Parkinson's disease: A unified framework. Neurosci Biobehav Rev 68, 727-740.

[6] DeMaagd G, Philip A (2015) Parkinson's disease and its management: Part 1: Disease entity, risk factors, pathophysiology, clinical presentation, and diagnosis. $P$ T 40, 504-532.

[7] Sampson TR, Debelius JW, Thron T, Janssen S, Shastri GG, Ilhan ZE, Challis C, Schretter CE, Rocha S, Gradinaru V, Chesselet MF, Keshavarzian A, Shannon KM, Krajmalnik-Brown R, Wittung-Stafshede P, Knight R, Mazmanian SK (2016) Gut microbiota regulate motor deficits and neuroinflammation in a model of Parkinson's disease. Cell 167, 1469-1480 e1412.

[8] Ilie OD, Ciobica A, McKenna J, Doroftei B, Mavroudis I (2020) Minireview on the relations between gut microflora and Parkinson's disease: Further biochemical (oxidative stress), inflammatory, and neurological particularities. Oxid Med Cell Longev 2020, 4518023.

[9] Carding S, Verbeke K, Vipond DT, Corfe BM, Owen LJ (2015) Dysbiosis of the gut microbiota in disease. Microb Ecol Health Dis 26, 26191.

[10] Luca M, Di Mauro M, Di Mauro M, Luca A (2019) Gut microbiota in Alzheimer's disease, depression, and type 2 diabetes mellitus: The role of oxidative stress. Oxid Med Cell Longev 2019, 4730539.

[11] Fitzgerald E, Murphy S, Martinson HA (2019) Alphasynuclein pathology and the role of the microbiota in Parkinson's disease. Front Neurosci 13, 369.

[12] Romano S, Savva GM, Bedarf JR, Charles IG, Hildebrand F, Narbad A (2021) Meta-analysis of the Parkinson's disease gut microbiome suggests alterations linked to intestinal inflammation. NPJ Parkinsons Dis 7, 27.

[13] Boertien JM, Pereira PAB, Aho VTE, Scheperjans F (2019) Increasing comparability and utility of gut microbiome studies in Parkinson's disease: A systematic review. J Parkinsons Dis 9, S297-S312.

[14] Hawkes CH, Del Tredici K, Braak H (2007) Parkinson's disease: A dual-hit hypothesis. Neuropathol Appl Neurobiol 33, 599-614.

[15] Hawkes CH, Del Tredici K, Braak H (2009) Parkinson's disease: The dual hit theory revisited. Ann N Y Acad Sci 1170, 615-622.

[16] Volpicelli-Daley L, Brundin P (2018) Prion-like propagation of pathology in Parkinson disease. Handb Clin Neurol 153, 321-335.

[17] Rietdijk CD, Perez-Pardo P, Garssen J, van Wezel RJ, Kraneveld AD (2017) Exploring Braak's hypothesis of Parkinson's disease. Front Neurol 8, 37.

[18] Furness JB, Callaghan BP, Rivera LR, Cho HJ (2014) The enteric nervous system and gastrointestinal innervation: Integrated local and central control. Adv Exp Med Biol 817, 39-71.

[19] Costa M, Brookes SJ, Hennig GW (2000) Anatomy and physiology of the enteric nervous system. Gut 47 Suppl 4, iv15-19; discussion iv26.

[20] Breit S, Kupferberg A, Rogler G, Hasler G (2018) Vagus nerve as modulator of the brain-gut axis in psychiatric and inflammatory disorders. Front Psychiatry 9, 44.

[21] Braak H, Del Tredici K, Rub U, de Vos RA, Jansen Steur EN, Braak E (2003) Staging of brain pathology related to sporadic Parkinson's disease. Neurobiol Aging 24, 197-211.

[22] Jellinger KA (2009) A critical evaluation of current staging of alpha-synuclein pathology in Lewy body disorders. Biochim Biophys Acta 1792, 730-740.

[23] Wakabayashi K, Takahashi H, Takeda S, Ohama E, Ikuta F (1989) Lewy bodies in the enteric nervous system in Parkinson's disease. Arch Histol Cytol 52(Suppl), 191-194.

[24] Braak H, de Vos RA, Bohl J, Del Tredici K (2006) Gastric alpha-synuclein immunoreactive inclusions in Meissner's and Auerbach's plexuses in cases staged for Parkinson's disease-related brain pathology. Neurosci Lett 396, 67-72.

[25] Lebouvier T, Neunlist M, Bruley des Varannes S, Coron E, Drouard A, N'Guyen JM, Chaumette T, Tasselli M, Paillusson S, Flamand M, Galmiche JP, Damier P, Derkinderen P (2010) Colonic biopsies to assess the neuropathology of Parkinson's disease and its relationship with symptoms. PLoS One 5, e12728.

[26] Gelpi E, Navarro-Otano J, Tolosa E, Gaig C, Compta Y, Rey MJ, Marti MJ, Hernandez I, Valldeoriola F, Rene R, Ribalta T (2014) Multiple organ involvement by alphasynuclein pathology in Lewy body disorders. Mov Disord 29, 1010-1018.

[27] Bloch A, Probst A, Bissig H, Adams H, Tolnay M (2006) Alpha-synuclein pathology of the spinal and peripheral autonomic nervous system in neurologically unimpaired elderly subjects. Neuropathol Appl Neurobiol 32, 284-295.

[28] Singaram C, Ashraf W, Gaumnitz EA, Torbey C, Sengupta A, Pfeiffer R, Quigley EM (1995) Dopaminergic defect of enteric nervous system in Parkinson's disease patients with chronic constipation. Lancet 346, 861-864.

[29] Pouclet H, Lebouvier T, Coron E, des Varannes SB, Rouaud T, Roy M, Neunlist M, Derkinderen P (2012) A comparison between rectal and colonic biopsies to detect Lewy pathology in Parkinson's disease. Neurobiol Dis 45, 305-309.

[30] Sanchez-Ferro A, Rabano A, Catalan MJ, RodriguezValcarcel FC, Fernandez Diez S, Herreros-Rodriguez J, Garcia-Cobos E, Alvarez-Santullano MM, Lopez-Manzanares L, Mosqueira AJ, Vela Desojo L, Lopez-Lozano JJ, Lopez-Valdes E, Sanchez-Sanchez R, Molina-Arjona JA (2015) In vivo gastric detection of alpha-synuclein inclusions in Parkinson's disease. Mov Disord 30, 517-524.

[31] Yan F, Chen Y, Li M, Wang Y, Zhang W, Chen X, Ye Q (2018) Gastrointestinal nervous system alpha-synuclein as a potential biomarker of Parkinson disease. Medicine (Baltimore) 97, e11337.

[32] Lee HJ, Jung KW, Chung SJ, Hong SM, Kim J, Lee JH, Hwang SW, Ryu HS, Kim MJ, Lee HS, Seo M, Park SH, Yang DH, Ye BD, Byeon JS, Choe J, Jung HY, Yang SK, Myung SJ (2018) Relation of enteric alpha-synuclein to gastrointestinal dysfunction in patients with Parkinson's disease and in neurologically intact subjects. J Neurogastroenterol Motil 24, 469-478.

[33] Stokholm MG, Danielsen EH, Hamilton-Dutoit SJ, Borghammer P (2016) Pathological alpha-synuclein in gastrointestinal tissues from prodromal Parkinson disease patients. Ann Neurol 79, 940-949.

[34] Killinger BA, Madaj Z, Sikora JW, Rey N, Haas AJ, Vepa Y, Lindqvist D, Chen H, Thomas PM, Brundin P, Brundin L, Labrie V (2018) The vermiform appendix impacts the risk of developing Parkinson's disease. Sci Transl Med 10, eaar5280. 
[35] Liu B, Fang F, Ye W, Wirdefeldt K (2020) Appendectomy, tonsillectomy and Parkinson's disease risk: A Swedish register-based study. Front Neurol 11, 510.

[36] Ishizuka M, Shibuya N, Takagi K, Hachiya H, Tago K, Suda K, Aoki T, Kubota K (2021) Appendectomy does not increase the risk of future emergence of Parkinson's disease: A meta-analysis. Am Surg, doi: 10.1177/ 0003134821989034

[37] Wang L, Magen I, Yuan PQ, Subramaniam SR, Richter F, Chesselet MF, Tache Y (2012) Mice overexpressing wild-type human alpha-synuclein display alterations in colonic myenteric ganglia and defecation. Neurogastroenterol Motil 24, e425-436.

[38] Hallett PJ, McLean JR, Kartunen A, Langston JW, Isacson $\mathrm{O}$ (2012) alpha-Synuclein overexpressing transgenic mice show internal organ pathology and autonomic deficits. Neurobiol Dis 47, 258-267.

[39] Del Tredici K, Hawkes CH, Ghebremedhin E, Braak H (2010) Lewy pathology in the submandibular gland of individuals with incidental Lewy body disease and sporadic Parkinson's disease. Acta Neuropathol 119, 703713.

[40] Monte FS, da Silva-Junior FP, Braga-Neto P, Nobre e Souza MA, de Bruin VM (2005) Swallowing abnormalities and dyskinesia in Parkinson's disease. Mov Disord 20, 457-462.

[41] Liu B, Fang F, Pedersen NL, Tillander A, Ludvigsson JF, Ekbom A, Svenningsson P, Chen H, Wirdefeldt K (2017) Vagotomy and Parkinson disease: A Swedish registerbased matched-cohort study. Neurology 88, 1996-2002.

[42] Svensson E, Horvath-Puho E, Thomsen RW, Djurhuus JC, Pedersen L, Borghammer P, Sorensen HT (2015) Vagotomy and subsequent risk of Parkinson's disease. Ann Neurol 78, 522-529.

[43] Jellinger KA (2008) A critical reappraisal of current staging of Lewy-related pathology in human brain. Acta Neuropathol 116, 1-16.

[44] Kim WS, Kagedal K, Halliday GM (2014) Alphasynuclein biology in Lewy body diseases. Alzheimers Res Ther 6, 73 .

[45] Beach TG, Adler CH, Sue LI, Vedders L, Lue L, White Iii CL, Akiyama H, Caviness JN, Shill HA, Sabbagh MN, Walker DG, Arizona Parkinson's Disease Consortium (2010) Multi-organ distribution of phosphorylated alpha-synuclein histopathology in subjects with Lewy body disorders. Acta Neuropathol 119, 689-702.

[46] Devos D, Lebouvier T, Lardeux B, Biraud M, Rouaud T, Pouclet H, Coron E, Bruley des Varannes S, Naveilhan P, Nguyen JM, Neunlist M, Derkinderen P (2013) Colonic inflammation in Parkinson's disease. Neurobiol Dis 50, $42-48$.

[47] Halliday G, Hely M, Reid W, Morris J (2008) The progression of pathology in longitudinally followed patients with Parkinson's disease. Acta Neuropathol 115, 409-415.

[48] McNaught KS, Shashidharan P, Perl DP, Jenner P, Olanow CW (2002) Aggresome-related biogenesis of Lewy bodies. Eur J Neurosci 16, 2136-2148.

[49] Tanaka M, Kim YM, Lee G, Junn E, Iwatsubo T, Mouradian MM (2004) Aggresomes formed by alpha-synuclein and synphilin-1 are cytoprotective. J Biol Chem 279, 4625-4631.

[50] Miguelez C, De Deurwaerdere P, Sgambato V (2020) Editorial: Non-dopaminergic systems in Parkinson's disease. Front Pharmacol 11, 593822.
[51] Hung AY, Schwarzschild MA (2014) Treatment of Parkinson's disease: What's in the non-dopaminergic pipeline? Neurotherapeutics 11, 34-46.

[52] Mertsalmi TH, Aho VTE, Pereira PAB, Paulin L, Pekkonen E, Auvinen P, Scheperjans F (2017) More than constipation - bowel symptoms in Parkinson's disease and their connection to gut microbiota. Eur J Neurol 24, 1375-1383.

[53] Dutkiewicz J, Szlufik S, Nieciecki M, Charzynska I, Krolicki L, Smektala P, Friedman A (2015) Small intestine dysfunction in Parkinson's disease. J Neural Transm (Vienna) 122, 1659-1661.

[54] Yu QJ, Yu SY, Zuo LJ, Lian TH, Hu Y, Wang RD, Piao YS, Guo P, Liu L, Jin Z, Li LX, Chan P, Chen SD, Wang XM, Zhang W (2018) Parkinson disease with constipation: Clinical features and relevant factors. Sci Rep 8, 567.

[55] Postuma RB, Gagnon JF, Pelletier A, Montplaisir J (2013) Prodromal autonomic symptoms and signs in Parkinson's disease and dementia with Lewy bodies. Mov Disord 28, 597-604.

[56] Abbott RD, Petrovitch H, White LR, Masaki KH, Tanner CM, Curb JD, Grandinetti A, Blanchette PL, Popper JS, Ross GW (2001) Frequency of bowel movements and the future risk of Parkinson's disease. Neurology 57, 456-462.

[57] Bharucha AE, Lacy BE (2020) Mechanisms, evaluation, and management of chronic constipation. Gastroenterology 158, 1232-1249 e 1233 .

[58] Jost WH (1997) Gastrointestinal motility problems in patients with Parkinson's disease. Effects of antiparkinsonian treatment and guidelines for management. Drugs Aging 10, 249-258.

[59] Pfeiffer RF (2003) Gastrointestinal dysfunction in Parkinson's disease. Lancet Neurol 2, 107-116.

[60] Ashraf W, Wszolek ZK, Pfeiffer RF, Normand M, Maurer K, Srb F, Edwards LL, Quigley EM (1995) Anorectal function in fluctuating (on-off) Parkinson's disease: Evaluation by combined anorectal manometry and electromyography. Mov Disord 10, 650-657.

[61] Ashraf W, Pfeiffer RF, Quigley EM (1994) Anorectal manometry in the assessment of anorectal function in Parkinson's disease: A comparison with chronic idiopathic constipation. Mov Disord 9, 655-663.

[62] Byrne KG, Pfeiffer R, Quigley EM (1994) Gastrointestinal dysfunction in Parkinson's disease. A report of clinical experience at a single center. J Clin Gastroenterol 19 11-16.

[63] Villumsen M, Aznar S, Pakkenberg B, Jess T, Brudek T (2019) Inflammatory bowel disease increases the risk of Parkinson's disease: A Danish nationwide cohort study 1977-2014. Gut 68, 18-24.

[64] Weimers P, Halfvarson J, Sachs MC, Saunders-Pullman R, Ludvigsson JF, Peter I, Burisch J, Olen O (2019) Inflammatory bowel disease and Parkinson's disease: A nationwide Swedish cohort study. Inflamm Bowel Dis 25, 111-123.

[65] Kumari U, Tan EK (2009) LRRK2 in Parkinson's disease: Genetic and clinical studies from patients. FEBS J 276, 6455-6463.

[66] Thomas GA, Rhodes J, Green JT, Richardson C (2000) Role of smoking in inflammatory bowel disease: Implications for therapy. Postgrad Med J 76, 273-279.

[67] Li X, Li W, Liu G, Shen X, Tang Y (2015) Association between cigarette smoking and Parkinson's disease: A meta-analysis. Arch Gerontol Geriatr 61, 510-516. 
[68] Derkinderen P, Shannon KM, Brundin P (2014) Gut feelings about smoking and coffee in Parkinson's disease. Mov Disord 29, 976-979.

[69] Bassotti G, Germani U, Pagliaricci S, Plesa A, Giulietti O, Mannarino E, Morelli A (1998) Esophageal manometric abnormalities in Parkinson's disease. Dysphagia 13, 28-31.

[70] Unger MM, Hattemer K, Moller JC, Schmittinger K, Mankel K, Eggert K, Strauch K, Tebbe JJ, Keil B, Oertel WH, Heverhagen JT, Knake S (2010) Real-time visualization of altered gastric motility by magnetic resonance imaging in patients with Parkinson's disease. Mov Disord 25, 623-628.

[71] Park A, Stacy M (2009) Non-motor symptoms in Parkinson's disease. J Neurol 256(Suppl 3), 293-298.

[72] Stacy M (2011) Nonmotor symptoms in Parkinson's disease. Int J Neurosci 121(Suppl 2), 9-17.

[73] Heetun ZS, Quigley EM (2012) Gastroparesis and Parkinson's disease: A systematic review. Parkinsonism Relat Disord 18, 433-440.

[74] Dukowicz AC, Lacy BE, Levine GM (2007) Small intestinal bacterial overgrowth: A comprehensive review. Gastroenterol Hepatol (N Y) 3, 112-122.

[75] Suttrup I, Warnecke T (2016) Dysphagia in Parkinson's disease. Dysphagia 31, 24-32.

[76] Ali GN, Wallace KL, Schwartz R, DeCarle DJ, Zagami AS, Cook IJ (1996) Mechanisms of oral-pharyngeal dysphagia in patients with Parkinson's disease. Gastroenterology 110, 383-392.

[77] Kalf JG, de Swart BJ, Bloem BR, Munneke M (2012) Prevalence of oropharyngeal dysphagia in Parkinson's disease: A meta-analysis. Parkinsonism Relat Disord 18, 311-315.

[78] Tanei ZI, Saito Y, Ito S, Matsubara T, Motoda A, Yamazaki M, Sakashita Y, Kawakami I, Ikemura M, Tanaka S, Sengoku R, Arai T, Murayama S (2021) Lewy pathology of the esophagus correlates with the progression of Lewy body disease: A Japanese cohort study of autopsy cases. Acta Neuropathol 141, 25-37.

[79] Su A, Gandhy R, Barlow C, Triadafilopoulos G (2017) Clinical and manometric characteristics of patients with Parkinson's disease and esophageal symptoms. Dis Esophagus 30, 1-6.

[80] Bushmann M, Dobmeyer SM, Leeker L, Perlmutter JS (1989) Swallowing abnormalities and their response to treatment in Parkinson's disease. Neurology 39, 1309-1314.

[81] Potulska A, Friedman A, Krolicki L, Spychala A (2003) Swallowing disorders in Parkinson's disease. Parkinsonism Relat Disord 9, 349-353.

[82] Mu L, Sobotka S, Chen J, Su H, Sanders I, Nyirenda T, Adler CH, Shill HA, Caviness JN, Samanta JE, Sue LI, Beach TG, Arizona Parkinson's Disease Consortium (2013) Parkinson disease affects peripheral sensory nerves in the pharynx. J Neuropathol Exp Neurol 72, 614-623.

[83] Tjaden K (2008) Speech and swallowing in Parkinson's disease. Top Geriatr Rehabil 24, 115-126.

[84] Goldman JG, Postuma R (2014) Premotor and nonmotor features of Parkinson's disease. Curr Opin Neurol 27, 434-441.

[85] Srivanitchapoom P, Pandey S, Hallett M (2014) Drooling in Parkinson's disease: A review. Parkinsonism Relat Disord 20, 1109-1118.

[86] Kalf JG, Munneke M, van den Engel-Hoek L, de Swart BJ, Borm GF, Bloem BR, Zwarts MJ (2011) Pathophysiology of diurnal drooling in Parkinson's disease. Mov Disord 26, 1670-1676.

[87] Nobrega AC, Rodrigues B, Melo A (2008) Is silent aspiration a risk factor for respiratory infection in Parkinson's disease patients? Parkinsonism Relat Disord 14, 646-648.

[88] Chen H, Zhang SM, Hernan MA, Willett WC, Ascherio A (2002) Diet and Parkinson's disease: A potential role of dairy products in men. Ann Neurol 52, 793-801.

[89] Baldini F, Hertel J, Sandt E, Thinnes CC, NeubergerCastillo L, Pavelka L, Betsou F, Kruger R, Thiele I, Consortium N-P (2020) Parkinson's disease-associated alterations of the gut microbiome predict disease-relevant changes in metabolic functions. BMC Biol 18, 62 .

[90] Cornelis MC (2019) The impact of caffeine and coffee on human health. Nutrients 11, 416.

[91] Ascherio A, Zhang SM, Hernan MA, Kawachi I, Colditz GA, Speizer FE, Willett WC (2001) Prospective study of caffeine consumption and risk of Parkinson's disease in men and women. Ann Neurol 50, 56-63.

[92] Hong CT, Chan L, Bai CH (2020) The effect of caffeine on the risk and progression of Parkinson's disease: A metaanalysis. Nutrients 12, 1860.

[93] Fall PA, Fredrikson M, Axelson O, Granerus AK (1999) Nutritional and occupational factors influencing the risk of Parkinson's disease: A case-control study in southeastern Sweden. Mov Disord 14, 28-37.

[94] Schiffmann SN, Fisone G, Moresco R, Cunha RA, Ferre S (2007) Adenosine A2A receptors and basal ganglia physiology. Prog Neurobiol 83, 277-292.

[95] Cieslak M, Komoszynski M, Wojtczak A (2008) Adenosine A(2A) receptors in Parkinson's disease treatment. Purinergic Signal 4, 305-312.

[96] Yadav S, Gupta SP, Srivastava G, Srivastava PK, Singh MP (2012) Role of secondary mediators in caffeine-mediated neuroprotection in maneb- and paraquat-induced Parkinson's disease phenotype in the mouse. Neurochem Res 37, 875-884.

[97] Chen JF, Xu K, Petzer JP, Staal R, Xu YH, Beilstein M, Sonsalla PK, Castagnoli K, Castagnoli N, Jr., Schwarzschild MA (2001) Neuroprotection by caffeine and $\mathrm{A}(2 \mathrm{~A})$ adenosine receptor inactivation in a model of Parkinson's disease. J Neurosci 21, RC143.

[98] Barranco Quintana JL, Allam MF, Del Castillo AS, Navajas RF (2009) Parkinson's disease and tea: A quantitative review. J Am Coll Nutr 28, 1-6.

[99] Preux PM, Condet A, Anglade C, Druet-Cabanac M, Debrock C, Macharia W, Couratier P, Boutros-Toni F, Dumas M (2000) Parkinson's disease and environmental factors. Matched case-control study in the Limousin region, France. Neuroepidemiology 19, 333-337.

[100] Li FJ, Ji HF, Shen L (2012) A meta-analysis of tea drinking and risk of Parkinson's disease. Scientific WorldJournal 2012, 923464.

[101] Qi H, Li S (2014) Dose-response meta-analysis on coffee, tea and caffeine consumption with risk of Parkinson's disease. Geriatr Gerontol Int 14, 430-439.

[102] Zhen C, Li D, Wang H, Wang P, Zhang W, Yu J, Xinjuan Yu, Wang X (2019) Tea consumption and risk of Parkinson's disease: A meta-analysis. Neurology Asia 24, 31-40.

[103] Yang CS, Landau JM (2000) Effects of tea consumption on nutrition and health. $J$ Nutr 130, 2409-2412.

[104] Li R, Huang YG, Fang D, Le WD (2004) (-)-Epigallocatechin gallate inhibits lipopolysaccharide-induced microglial activation and protects against inflammation- 
mediated dopaminergic neuronal injury. J Neurosci Res 78, 723-731.

[105] Cho HS, Kim S, Lee SY, Park JA, Kim SJ, Chun HS (2008) Protective effect of the green tea component, Ltheanine on environmental toxins-induced neuronal cell death. Neurotoxicology 29, 656-662.

[106] Checkoway H, Powers K, Smith-Weller T, Franklin GM, Longstreth WT, Jr., Swanson PD (2002) Parkinson's disease risks associated with cigarette smoking, alcohol consumption, and caffeine intake. Am J Epidemiol 155, 732-738.

[107] Saaksjarvi K, Knekt P, Lundqvist A, Mannisto S, Heliovaara M, Rissanen H, Jarvinen R (2013) A cohort study on diet and the risk of Parkinson's disease: The role of food groups and diet quality. Br J Nutr 109, 329-337.

[108] Kyrozis A, Ghika A, Stathopoulos P, Vassilopoulos D, Trichopoulos D, Trichopoulou A (2013) Dietary and lifestyle variables in relation to incidence of Parkinson's disease in Greece. Eur J Epidemiol 28, 67-77.

[109] Jiang W, Ju C, Jiang H, Zhang D (2014) Dairy foods intake and risk of Parkinson's disease: A dose-response metaanalysis of prospective cohort studies. Eur J Epidemiol 29, 613-619.

[110] Hughes KC, Gao X, Kim IY, Wang M, Weisskopf MG, Schwarzschild MA, Ascherio A (2017) Intake of dairy foods and risk of Parkinson disease. Neurology 89, 46-52.

[111] Weisskopf MG, O'Reilly E, Chen H, Schwarzschild MA, Ascherio A (2007) Plasma urate and risk of Parkinson's disease. Am J Epidemiol 166, 561-567.

[112] Schlesinger I, Schlesinger N (2008) Uric acid in Parkinson's disease. Mov Disord 23, 1653-1657.

[113] Shen C, Guo Y, Luo W, Lin C, Ding M (2013) Serum urate and the risk of Parkinson's disease: Results from a meta-analysis. Can J Neurol Sci 40, 73-79.

[114] Gao X, Chen H, Choi HK, Curhan G, Schwarzschild MA, Ascherio A (2008) Diet, urate, and Parkinson's disease risk in men. Am J Epidemiol 167, 831-838.

[115] Gao X, Chen H, Fung TT, Logroscino G, Schwarzschild MA, Hu FB, Ascherio A (2007) Prospective study of dietary pattern and risk of Parkinson disease. Am J Clin Nutr 86, 1486-1494.

[116] Gardener H, Caunca MR (2018) Mediterranean diet in preventing neurodegenerative diseases. Curr Nutr Rep 7, 10-20.

[117] Sofi F, Cesari F, Abbate R, Gensini GF, Casini A (2008) Adherence to Mediterranean diet and health status: Metaanalysis. BMJ 337, a1344.

[118] Xie Y, Feng H, Peng S, Xiao J, Zhang J (2017) Association of plasma homocysteine, vitamin B12 and folate levels with cognitive function in Parkinson's disease: A metaanalysis. Neurosci Lett 636, 190-195.

[119] Shen L (2015) Associations between B vitamins and Parkinson's disease. Nutrients 7, 7197-7208.

[120] Agim ZS, Cannon JR (2015) Dietary factors in the etiology of Parkinson's disease. Biomed Res Int 2015, 672838 .

[121] Schroecksnadel K, Leblhuber F, Fuchs D (2004) Effect of L-dopa on plasma homocysteine in PD patients: Relationship to B-vitamin status. Neurology 62, 676; author reply 676-677.

[122] Etminan M, Gill SS, Samii A (2005) Intake of vitamin E, vitamin C, and carotenoids and the risk of Parkinson's disease: A meta-analysis. Lancet Neurol 4, 362-365.
[123] Fullard ME, Duda JE (2020) A review of the relationship between vitamin D and Parkinson disease symptoms. Front Neurol 11, 454.

[124] Suzuki M, Yoshioka M, Hashimoto M, Murakami M, Noya M, Takahashi D, Urashima M (2013) Randomized, double-blind, placebo-controlled trial of vitamin D supplementation in Parkinson disease. Am J Clin Nutr 97, 1004-1013.

[125] Luo X, Ou R, Dutta R, Tian Y, Xiong H, Shang H (2018) Association between serum vitamin D levels and Parkinson's disease: A systematic review and meta-analysis. Front Neurol 9, 909.

[126] Hantikainen E, Trolle Lagerros Y, Ye W, Serafini M, Adami HO, Bellocco R, Bonn S (2021) Dietary antioxidants and the risk of Parkinson disease: The Swedish National March Cohort. Neurology 96, e895-e903.

[127] Qu Y, Chen X, Xu MM, Sun Q (2019) Relationship between high dietary fat intake and Parkinson's disease risk: A meta-analysis. Neural Regen Res 14, 2156-2163.

[128] de Lau LM, Bornebroek M, Witteman JC, Hofman A, Koudstaal PJ, Breteler MM (2005) Dietary fatty acids and the risk of Parkinson disease: The Rotterdam study. Neurology 64, 2040-2045.

[129] Bazinet RP, Laye S (2014) Polyunsaturated fatty acids and their metabolites in brain function and disease. Nat Rev Neurosci 15, 771-785.

[130] Fernstrom JD (1999) Effects of dietary polyunsaturated fatty acids on neuronal function. Lipids 34, 161-169.

[131] Kamel F, Goldman SM, Umbach DM, Chen H, Richardson G, Barber MR, Meng C, Marras C, Korell M, Kasten M, Hoppin JA, Comyns K, Chade A, Blair A, Bhudhikanok GS, Webster Ross G, William Langston J, Sandler DP, Tanner CM (2014) Dietary fat intake, pesticide use, and Parkinson's disease. Parkinsonism Relat Disord 20, 82-87.

[132] Gasior M, Rogawski MA, Hartman AL (2006) Neuroprotective and disease-modifying effects of the ketogenic diet. Behav Pharmacol 17, 431-439.

[133] Vanitallie TB, Nonas C, Di Rocco A, Boyar K, Hyams K, Heymsfield SB (2005) Treatment of Parkinson disease with diet-induced hyperketonemia: A feasibility study. Neurology 64, 728-730.

[134] Wang L, Xiong N, Huang J, Guo S, Liu L, Han C, Zhang G, Jiang H, Ma K, Xia Y, Xu X, Li J, Liu JY, Wang T (2017) Protein-restricted diets for ameliorating motor fluctuations in Parkinson's disease. Front Aging Neurosci 9, 206.

[135] Wang A, Lin Y, Wu Y, Zhang D (2015) Macronutrients intake and risk of Parkinson's disease: A meta-analysis. Geriatr Gerontol Int 15, 606-616.

[136] Wurtman RJ, Wurtman JJ, Regan MM, McDermott JM, Tsay RH, Breu JJ (2003) Effects of normal meals rich in carbohydrates or proteins on plasma tryptophan and tyrosine ratios. Am J Clin Nutr 77, 128-132.

[137] Murakami K, Miyake Y, Sasaki S, Tanaka K, Fukushima W, Kiyohara C, Tsuboi Y, Yamada T, Oeda T, Miki T, Kawamura N, Sakae N, Fukuyama H, Hirota Y, Nagai M, Fukuoka Kinki Parkinson's Disease Study Group (2010) Dietary glycemic index is inversely associated with the risk of Parkinson's disease: A case-control study in Japan. Nutrition 26, 515-521.

[138] Phillips MCL, Murtagh DKJ, Gilbertson LJ, Asztely FJS, Lynch CDP (2018) Low-fat versus ketogenic diet in Parkinson's disease: A pilot randomized controlled trial. Mov Disord 33, 1306-1314. 
[139] Jung CH, Choi KM (2017) Impact of high-carbohydrate diet on metabolic parameters in patients with type 2 diabetes. Nutrients $\mathbf{9}, 322$.

[140] Camargo Maluf F, Feder D, Alves de Siqueira Carvalho A (2019) Analysis of the relationship between type ii diabetes mellitus and Parkinson's disease: A systematic review. Parkinsons Dis 2019, 4951379.

[141] Athauda D, Maclagan K, Skene SS, Bajwa-Joseph M, Letchford D, Chowdhury K, Hibbert S, Budnik N, Zampedri L, Dickson J, Li Y, Aviles-Olmos I, Warner TT, Limousin P, Lees AJ, Greig NH, Tebbs S, Foltynie T (2017) Exenatide once weekly versus placebo in Parkinson's disease: A randomised, doubleblind, placebo-controlled trial. Lancet 390, 1664-1675.

[142] Bertilsson G, Patrone C, Zachrisson O, Andersson A, Dannaeus K, Heidrich J, Kortesmaa J, Mercer A, Nielsen E, Ronnholm H, Wikstrom L (2008) Peptide hormone exendin-4 stimulates subventricular zone neurogenesis in the adult rodent brain and induces recovery in an animal model of Parkinson's disease. J Neurosci Res 86, 326-338

[143] Bull MJ, Plummer NT (2014) Part 1: The human gut microbiome in health and disease. Integr Med (Encinitas) 13, 17-22.

[144] Collado MC, Rautava S, Aakko J, Isolauri E, Salminen S (2016) Human gut colonisation may be initiated in utero by distinct microbial communities in the placenta and amniotic fluid. Sci Rep 6, 23129.

[145] Keightley PC, Koloski NA, Talley NJ (2015) Pathways in gut-brain communication: Evidence for distinct gut-tobrain and brain-to-gut syndromes. Aust N Z J Psychiatry 49, 207-214.

[146] DeGruttola AK, Low D, Mizoguchi A, Mizoguchi E (2016) Current understanding of dysbiosis in disease in human and animal models. Inflamm Bowel Dis 22, 1137-1150.

[147] Fang X (2016) Potential role of gut microbiota and tissue barriers in Parkinson's disease and amyotrophic lateral sclerosis. Int J Neurosci 126, 771-776.

[148] Minato T, Maeda T, Fujisawa Y, Tsuji H, Nomoto K, Ohno K, Hirayama M (2017) Progression of Parkinson's disease is associated with gut dysbiosis: Two-year follow-up study. PLoS One 12, e0187307.

[149] Keshavarzian A, Green SJ, Engen PA, Voigt RM, Naqib A, Forsyth CB, Mutlu E, Shannon KM (2015) Colonic bacterial composition in Parkinson's disease. Mov Disord 30, 1351-1360.

[150] Bedarf JR, Hildebrand F, Coelho LP, Sunagawa S, Bahram M, Goeser F, Bork P, Wullner U (2017) Functional implications of microbial and viral gut metagenome changes in early stage L-DOPA-naive Parkinson's disease patients. Genome Med 9, 39.

[151] Scheperjans F, Aho V, Pereira PA, Koskinen K, Paulin L, Pekkonen E, Haapaniemi E, Kaakkola S, Eerola-Rautio J, Pohja M, Kinnunen E, Murros K, Auvinen P (2015) Gut microbiota are related to Parkinson's disease and clinical phenotype. Mov Disord 30, 350-358.

[152] Unger MM, Spiegel J, Dillmann KU, Grundmann D, Philippeit H, Burmann J, Fassbender K, Schwiertz A, Schafer KH (2016) Short chain fatty acids and gut microbiota differ between patients with Parkinson's disease and age-matched controls. Parkinsonism Relat Disord 32, 66-72.

[153] Li C, Cui L, Yang Y, Miao J, Zhao X, Zhang J, Cui G, Zhang Y (2019) Gut microbiota differs between Parkin- son's disease patients and healthy controls in Northeast China. Front Mol Neurosci 12, 171.

[154] Zhang F, Yue L, Fang X, Wang G, Li C, Sun X, Jia X, Yang J, Song J, Zhang Y, Guo C, Ma G, Sang M, Chen F, Wang P (2020) Altered gut microbiota in Parkinson's disease patients/healthy spouses and its association with clinical features. Parkinsonism Relat Disord 81, 84-88.

[155] Tan AH, Mahadeva S, Thalha AM, Gibson PR, Kiew CK, Yeat CM, Ng SW, Ang SP, Chow SK, Tan CT, Yong HS, Marras C, Fox SH, Lim SY (2014) Small intestinal bacterial overgrowth in Parkinson's disease. Parkinsonism Relat Disord 20, 535-540.

[156] Niu XL, Liu L, Song ZX, Li Q, Wang ZH, Zhang JL, Li HH (2016) Prevalence of small intestinal bacterial overgrowth in Chinese patients with Parkinson's disease. J Neural Transm (Vienna) 123, 1381-1386.

[157] Cassani E, Barichella M, Cancello R, Cavanna F, Iorio L, Cereda E, Bolliri C, Zampella Maria P, Bianchi F, Cestaro B, Pezzoli G (2015) Increased urinary indoxyl sulfate (indican): New insights into gut dysbiosis in Parkinson's disease. Parkinsonism Relat Disord 21, 389-393.

[158] Nair AT, Ramachandran V, Joghee NM, Antony S, Ramalingam G (2018) Gut microbiota dysfunction as reliable non-invasive early diagnostic biomarkers in the pathophysiology of Parkinson's disease: A critical review. $J$ Neurogastroenterol Motil 24, 30-42.

[159] Petrov VA, Saltykova IV, Zhukova IA, Alifirova VM, Zhukova NG, Dorofeeva YB, Tyakht AV, Kovarsky BA, Alekseev DG, Kostryukova ES, Mironova YS, Izhboldina OP, Nikitina MA, Perevozchikova TV, Fait EA, Babenko VV, Vakhitova MT, Govorun VM, Sazonov AE (2017) Analysis of gut microbiota in patients with Parkinson's disease. Bull Exp Biol Med 162, 734-737.

[160] Gerhardt S, Mohajeri MH (2018) Changes of colonic bacterial composition in Parkinson's disease and other neurodegenerative diseases. Nutrients 10, 708.

[161] Engevik MA, Morra CN, Roth D, Engevik K, Spinler JK, Devaraj S, Crawford SE, Estes MK, Kalkum M, Versalovic J (2019) Microbial metabolic capacity for intestinal folate production and modulation of host folate receptors. Front Microbiol 10, 2305.

[162] Uebanso T, Shimohata T, Mawatari K, Takahashi A (2020) Functional roles of B-vitamins in the gut and gut microbiome. Mol Nutr Food Res 64, e2000426.

[163] Andrews ZB, Erion D, Beiler R, Liu ZW, Abizaid A, Zigman J, Elsworth JD, Savitt JM, DiMarchi R, Tschoep M, Roth RH, Gao XB, Horvath TL (2009) Ghrelin promotes and protects nigrostriatal dopamine function via a UCP2-dependent mitochondrial mechanism. J Neurosci 29, 14057-14065.

[164] Bergstrom KS, Xia L (2013) Mucin-type O-glycans and their roles in intestinal homeostasis. Glycobiology 23, 1026-1037.

[165] Heintz-Buschart A, Pandey U, Wicke T, Sixel-Doring F, Janzen A, Sittig-Wiegand E, Trenkwalder C, Oertel WH, Mollenhauer B, Wilmes P (2018) The nasal and gut microbiome in Parkinson's disease and idiopathic rapid eye movement sleep behavior disorder. Mov Disord 33, 88-98.

[166] Li Y, Kang W, Yang Q, Zhang L, Zhang L, Dong F, Chen S, Liu J (2017) Predictive markers for early conversion of iRBD to neurodegenerative synucleinopathy diseases. Neurology 88, 1493-1500.

[167] De Filippis F, Pellegrini N, Laghi L, Gobbetti M, Ercolini D (2016) Unusual sub-genus associations of faecal 
Prevotella and Bacteroides with specific dietary patterns. Microbiome 4, 57.

[168] Pradhan G, Samson SL, Sun Y (2013) Ghrelin: Much more than a hunger hormone. Curr Opin Clin Nutr Metab Care 16, 619-624.

[169] Ohkusa T, Koido S, Nishikawa Y, Sato N (2019) Gut microbiota and chronic constipation: A review and update. Front Med (Lausanne) 6, 19.

[170] Cassani E, Privitera G, Pezzoli G, Pusani C, Madio C, Iorio L, Barichella M (2011) Use of probiotics for the treatment of constipation in Parkinson's disease patients. Minerva Gastroenterol Dietol 57, 117-121.

[171] Willemsen LE, Koetsier MA, van Deventer SJ, van Tol EA (2003) Short chain fatty acids stimulate epithelial mucin 2 expression through differential effects on prostaglandin $\mathrm{E}(1)$ and $\mathrm{E}(2)$ production by intestinal myofibroblasts. Gut 52, 1442-1447.

[172] Pituch A, Walkowiak J, Banaszkiewicz A (2013) Butyric acid in functional constipation. Prz Gastroenterol 8, 295-298.

[173] Silva YP, Bernardi A, Frozza RL (2020) The role of short-chain fatty acids from gut microbiota in gut-brain communication. Front Endocrinol (Lausanne) 11, 25.

[174] Bach Knudsen KE, Serena A, Canibe N, Juntunen KS (2003) New insight into butyrate metabolism. Proc Nutr Soc 62, 81-86.

[175] St Laurent R, O’Brien LM, Ahmad ST (2013) Sodium butyrate improves locomotor impairment and early mortality in a rotenone-induced Drosophila model of Parkinson's disease. Neuroscience 246, 382-390.

[176] Everard A, Belzer C, Geurts L, Ouwerkerk JP, Druart C, Bindels LB, Guiot Y, Derrien M, Muccioli GG, Delzenne NM, de Vos WM, Cani PD (2013) Cross-talk between Akkermansia muciniphila and intestinal epithelium controls diet-induced obesity. Proc Natl Acad Sci U S A 110, 9066-9071.

[177] de Vos WM (2015) Microbial biofilms and the human intestinal microbiome. NPJ Biofilms Microbiomes 1, 15005 .

[178] Geerlings SY, Kostopoulos I, de Vos WM, Belzer C (2018) Akkermansia muciniphila in the human gastrointestinal tract: When, where, and how? Microorganisms 6, 75.

[179] Dobbs RJ, Charlett A, Dobbs SM, Weller C, Peterson DW (2000) Parkinsonism: Differential age-trend in Helicobacter pylori antibody. Aliment Pharmacol Ther 14, 1199-1205.

[180] Camci G, Oguz S (2016) Association between Parkinson's disease and Helicobacter pylori. J Clin Neurol 12, 147-150.

[181] Tan AH, Mahadeva S, Marras C, Thalha AM, Kiew CK, Yeat CM, Ng SW, Ang SP, Chow SK, Loke MF, Vadivelu JS, Ibrahim N, Yong HS, Tan CT, Fox SH, Lang AE, Lim SY (2015) Helicobacter pylori infection is associated with worse severity of Parkinson's disease. Parkinsonism Relat Disord 21, 221-225.
[182] Weller C, Charlett A, Oxlade NL, Dobbs SM, Dobbs RJ, Peterson DW, Bjarnason IT (2005) Role of chronic infection and inflammation in the gastrointestinal tract in the etiology and pathogenesis of idiopathic parkinsonism. Part 3: Predicted probability and gradients of severity of idiopathic parkinsonism based on $\mathrm{H}$. pylori antibody profile. Helicobacter 10, 288-297.

[183] Bjarnason IT, Charlett A, Dobbs RJ, Dobbs SM, Ibrahim MA, Kerwin RW, Mahler RF, Oxlade NL, Peterson DW, Plant JM, Price AB, Weller C (2005) Role of chronic infection and inflammation in the gastrointestinal tract in the etiology and pathogenesis of idiopathic parkinsonism. Part 2: Response of facets of clinical idiopathic parkinsonism to Helicobacter pylori eradication. A randomized, doubleblind, placebo-controlled efficacy study. Helicobacter 10, 276-287.

[184] Dobbs RJ, Charlett A, Dobbs SM, Weller C, MA AI, Iguodala O, Smee C, Plant JM, Lawson AJ, Taylor D, Bjarnason I (2012) Leukocyte-subset counts in idiopathic parkinsonism provide clues to a pathogenic pathway involving small intestinal bacterial overgrowth. A surveillance study. Gut Pathog 4, 12.

[185] Schulz JD, Hawkes EL, Shaw CA (2006) Cycad toxins, Helicobacter pylori and parkinsonism: Cholesterol glucosides as the common denomenator. Med Hypotheses 66, 1222-1226.

[186] Dobbs RJ, Dobbs SM, Weller C, Charlett A, Bjarnason IT, Curry A, Ellis DS, Ibrahim MA, McCrossan MV, O'Donohue J, Owen RJ, Oxlade NL, Price AB, Sanderson JD, Sudhanva M, Williams J (2008) Helicobacter hypothesis for idiopathic parkinsonism: Before and beyond. Helicobacter 13, 309-322.

[187] Kountouras J, Zavos C, Polyzos SA, Deretzi G, Vardaka E, Giartza-Taxidou E, Katsinelos P, Rapti E, Chatzopoulos D, Tzilves D, Stergiopoulos C, Christodoulou K (2012) Helicobacter pylori infection and Parkinson's disease: Apoptosis as an underlying common contributor. Eur $J$ Neurol 19, e56.

[188] Li X, Feng X, Jiang Z, Jiang Z (2021) Association of small intestinal bacterial overgrowth with Parkinson's disease: A systematic review and meta-analysis. Gut Pathog 13, 25.

[189] Fasano A, Bove F, Gabrielli M, Petracca M, Zocco MA, Ragazzoni E, Barbaro F, Piano C, Fortuna S, Tortora A, Di Giacopo R, Campanale M, Gigante G, Lauritano EC, Navarra P, Marconi S, Gasbarrini A, Bentivoglio AR (2013) The role of small intestinal bacterial overgrowth in Parkinson's disease. Mov Disord 28, 1241-1249.

[190] Heinzel S, Aho VTE, Suenkel U, von Thaler AK, Schulte C, Deuschle C, Paulin L, Hantunen S, Brockmann K, Eschweiler GW, Maetzler W, Berg D, Auvinen P, Scheperjans F (2020) Gut microbiome signatures of risk and prodromal markers of Parkinson disease. Ann Neurol 88, 320-331. 